\title{
Increased risk of endometriosis in patients with endometritis - a nationwide cohort study involving 84,150 individuals
}

\author{
Kent Yu-Hsien Lin ${ }^{1}$, Cherry Yin-Yi Chang ${ }^{2,3}$, Wu-Chou Lin ${ }^{3,4 *}$, Lei Wan ${ }^{3,4,5 *}$ \\ ${ }^{1}$ Department of Obstetrics and Gynecology, Women and Children's Health, Royal North Shore Hospital, Sydney, NSW, Australia \\ ${ }^{2}$ School of Medicine, China Medical University, Taichung, Taiwan \\ ${ }^{3}$ Department of Obstetrics and Gynecology, China Medical University Hospital, Taichung, Taiwan \\ ${ }^{4}$ School of Chinese Medicine, China Medical University, Taichung, Taiwan \\ ${ }^{5}$ Department of Biotechnology, Asia University, Taichung, Taiwan \\ *Wu-Chou Lin and Lei Wan contributed equally to this work.
}

\begin{abstract}
Objectives: To evaluate the incidence of endometriosis among endometritis patients and its association with confounding comorbidities.

Material and methods: A population-based, retrospective cohort study of women aged between 20 to 55 years, who were newly diagnosed with endometritis between 2000 to 2013. A total of 16,830 endometritis patients and 67,230 non-endometritis individuals were enrolled by accessing data from the National Health Insurance Research Database of Taiwan. The comorbidities accessed were uterine leiomyoma, rheumatoid arthritis, ovarian cancer, infertility and allergic diseases. Results: The mean follow-up period was 9.15 years for the non-endometritis cohort and 9.13 years for the endometritis cohort. There were significantly higher percentages of uterine leiomyoma, rheumatoid arthritis, infertility, ovarian cancer and allergic diseases in the endometritis cohort than in the non-endometritis cohort. Patients with endometritis had a 1.5-fold increased risk of their condition advancing to endometriosis ( $\mathrm{HR} 1.58,95 \% \mathrm{Cl} 1.48-1.68$ ).

Conclusions: Our results suggest that patients with endometritis exhibited a positive correlation in developing endometriosis.

Key words: endometritis; inflammation; microbial infection; endometriosis
\end{abstract}

\section{INTRODUCTION}

Endometriosis is defined by the presence of endometrial epithelial and stromal tissue outside the uterine cavity. It is not considered a malignant disease, but it can lead to common symptoms such as dysmenorrhea, dyspareunia, pelvic pain, and reduced fertility. About $10 \%$ of all menstruating women have endometriosis [1, 2].

The processes associated with the pathogenesis of endometriosis remain undetermined. Currently, the most agreed upon hypothesis is that of retrograde menstruation, through which endometrial tissues flow back through the fallopian tubes into the peritoneal cavity, where they attach and develop to form pelvic endometriosis [3]. It should be noted that about $90 \%$ of women exhibit retrograde menstruation; however, in only $6-10 \%$ of them is endometriosis established $[1,4]$. Therefore, retrograde menstruation can only be considered as a risk factor, and not an exact pathogenic factor. Variations in the genetic, biochemical, and physiological properties of the ovaries, rectovaginal septum, and peritoneum mean that endometriosis may result from diverse circumstances.

Endometritis is characterized as a microbial infectious and inflammatory disease. Bacteria commonly detected in patients with endometritis include streptococcus species, Escherichia coli, Enterococcus faecalis, staphylococcus 


\begin{tabular}{|c|c|c|c|}
\hline \multicolumn{2}{|c|}{$\begin{array}{c}\text { Participants in LHID } \\
2000 \text { database }(1996-2013) \\
(n=1,000,000) \\
\end{array}$} & & \\
\hline & & \multicolumn{2}{|c|}{$\begin{array}{l}\text { Include } \\
\text { Patients with at least } \\
\text { two outpatient visits or } \\
\text { one inpatient care with } \\
\text { endometritis diagnosis } \\
\text { (ICD-9:615) }\end{array}$} \\
\hline \multicolumn{4}{|c|}{$\begin{array}{l}\text { Patients with endometritis } \\
\qquad \begin{array}{l}(1996-2013) \\
(n=23,837)\end{array}\end{array}$} \\
\hline & & \multicolumn{2}{|c|}{$\begin{array}{l}\text { Exclusion Criteria } \\
\text { 1. Endometritis date out } \\
\text { of the study period } \\
(2000-2012)(n=2840) \\
\text { 2. Male }(n=4) \\
\text { 3. Age }<20 \text { or } \\
\text { age } \geq 55(n=2,410)\end{array}$} \\
\hline & & \multirow{2}{*}{\multicolumn{2}{|c|}{$\begin{array}{l}\text { Using the same exclusion } \\
\text { criteria as case cohort } \\
\text { and } 1: 4 \text { frequency mat- } \\
\text { ched by } 5 \text {-year age and } \\
\text { diagnosis year }\end{array}$}} \\
\hline & $\begin{array}{l}\text { Patients in } 2000 \text { to } \\
12 \text { newly diagnosed as } \\
\text { dometritis ( } n=18,583 \text { ) }\end{array}$ & & \\
\hline \multicolumn{4}{|c|}{$\begin{array}{l}\text { 1. Excluded patients with a preexist- } \\
\text { ing diagnosis or on the same day } \\
\text { of endometriosis ( } n=904) \\
\text { 2. Excluded patients who can not } \\
\text { match } 4 \text { controls }(n=849)\end{array}$} \\
\hline \multicolumn{4}{|c|}{$\begin{array}{l}16,830 \text { endometritis patients and } 67,320 \text { non-endome- } \\
\text { tritis patients followed up to endometriosis or until the } \\
\text { end of the study }(2013 / 12 / 31)\end{array}$} \\
\hline
\end{tabular}

Figure 1. Subject selection process

species, Mycoplasma genitalium, Mycoplasma hominis, Ureaplasma urealyticum, proteus species, Klebsiella pneumoniae, Pseudomonas aeruginosa, Gardnerella vaginalis, and Corynebacterium [5]. Yeasts such as Saccharomyces cerevisiae and candida species are also present in the endometrium of patients with endometritis $[5,6]$. Changes in the distribution of lactobacilli species in the female reproductive tract may represent another risk factor for endometritis $[7,8]$.

\section{Objectives}

The aim of this study was to explore the possible association between endometritis and endometriosis. We analyzed data from the National Health Insurance Research Database (NHRID) of Taiwan through a retrospective cohort study to demonstrate whether patients with endometritis have a higher risk of endometriosis.

\section{MATERIAL AND METHODS \\ Data source}

We used the Longitudinal Health Insurance Database 2000 which randomly selected one million participants from the NHIRD of Taiwan and made sure that the age and sex distributions were comparable to those of the Taiwanese population. The identity of each participant was protected by encrypting the identification number before the data were released. All history diagnoses in the database were coded according to the International Classification of Diseases, Ninth Revision, Clinical Modification (ICD-9-CM). The Research Ethics Committee of China Medical University and Hospital in Taiwan approved the study (CMUH-104-REC2-115-R3).

\section{Study population}

We enrolled 18,583 female patients who were aged between 20 and 55 years and newly diagnosed as having endometritis (ICD-9-CM 615) from 2000 to 2012; the diagnosis date was defined as the index date. The non-endometritis cohort was matched 1:4 by age (in 5-year bands) and index year. We excluded patients with a pre-existing diagnosis of endometriosis (ICD-9-CM 615.0-615.9) and those who could not match 4 controls. The same exclusion criteria were used in the non-endometritis cohort as in the endometritis cohort. A total of 16,830 endometritis patients and 67,320 non-endometritis patients were followed up to development of endometriosis, death, or until the end of the study (2013/12/31), whichever came first. We collected both demographic characteristics and endometriosis comorbidity history as potential confounders. The comorbidities included uterine leiomyoma (ICD-9-CM 218), rheumatoid arthritis (ICD-9-CM 714.0), ovarian cancer (ICD-9-CM 183.0), multiple sclerosis (ICD-9-CM $340)$, infertility (ICD-9-CM 628), cervical cancer (ICD-9-CM 180), breast cancer (ICD-9-CM 174), autoimmune diseases (ICD-9-CM 710.0), and allergic diseases (ICD-9-CM 477) (Fig. 1).

\section{Statistical analysis}

Distribution of age, sex, and comorbidities between the endometritis cohort and non-endometritis cohort were described in terms of numbers and percentages and tested using the Chi-square test and T test. The hazard ratio (HR) and 95\% confidence interval $(95 \% \mathrm{Cl})$ were estimated using the Cox proportional hazard model for evaluating the association between endometritis and endometriosis. The multivariate Cox proportional hazard model was used to estimate the HRs after adjustment for age, gender, and comorbidities, which were notably different in the univariate model or with/without comorbidity. Analysis of stratification by age and comorbidity was performed to explore the association between endometri- 
Table 1. Baseline characteristics of patients

\begin{tabular}{|c|c|c|c|c|c|}
\hline & \multicolumn{4}{|c|}{ Endometritis } & \multirow{4}{*}{ p-value* } \\
\hline & \multicolumn{2}{|l|}{ No } & \multicolumn{2}{|l|}{ Yes } & \\
\hline & \multicolumn{2}{|c|}{$(n=67,320)$} & \multicolumn{2}{|c|}{$(n=16,830)$} & \\
\hline & $n$ & $\%$ & $n$ & $\%$ & \\
\hline Age & & & & & $>0.99$ \\
\hline $20-25$ & 12736 & 18.92 & 3184 & 18.92 & \\
\hline $25-30$ & 13392 & 19.89 & 3348 & 19.89 & \\
\hline $30-35$ & 11728 & 17.42 & 2932 & 17.42 & \\
\hline $35-40$ & 10448 & 15.52 & 2612 & 15.52 & \\
\hline $40-45$ & 9028 & 13.41 & 2257 & 13.41 & \\
\hline $45-50$ & 6532 & 9.7 & 1633 & 9.7 & \\
\hline $50-55$ & 3456 & 5.13 & 864 & 5.13 & \\
\hline Mean (SD) & \multicolumn{2}{|c|}{$34.2(9.1)$} & \multicolumn{2}{|c|}{$34.1(9.0)$} & $0.467 a$ \\
\hline Childbirth & & & & & $<0.001$ \\
\hline No & 51747 & 76.87 & 11289 & 67.08 & \\
\hline Yes & 15573 & 23.13 & 5541 & 32.92 & \\
\hline \multicolumn{6}{|l|}{ Comorbidity } \\
\hline Uterine leiomyoma & 2544 & 3.78 & 1104 & 6.56 & $<0.001$ \\
\hline Rheumatoid arthritis & 416 & 0.62 & 140 & 0.83 & 0.002 \\
\hline Ovarian cancer & 40 & 0.06 & 2 & 0.01 & 0.014 \\
\hline Multiple sclerosis & 20 & 0.03 & 7 & 0.04 & 0.441 \\
\hline Infertility & 1539 & 2.29 & 698 & 4.15 & $<0.001$ \\
\hline Cervical cancer & 130 & 0.19 & 33 & 0.2 & 0.938 \\
\hline Breast cancer & 202 & 0.3 & 52 & 0.31 & 0.85 \\
\hline Autoimmune & 263 & 0.39 & 72 & 0.43 & 0.494 \\
\hline Allergic disease & 10138 & 15.06 & 2978 & 17.69 & $<0.001$ \\
\hline
\end{tabular}

*Chi-square test; at-test

tis and endometriosis among specific populations. Cumulative incidence curves for endometriosis were computed using the Kaplan-Meier method, and differences between the endometritis cohort and the non-endometritis cohort were tested using a log-rank test. All statistical analyses were performed using Stata Statistical Software version 14 (StataCorp, College Station, TX, USA). Statistical significance was determined using two-tailed tests $(p<0.05)$.

\section{RESULTS}

The mean ages were 34.2 years and 34.1 years in the non-endometritis cohort and endometritis cohort, respectively. There were significantly higher percentages of uterine leiomyoma, rheumatoid arthritis, infertility, and allergic diseases in the endometritis cohort than in the non-endometritis cohort. The endometritis cohort also had a considerably lower percentage of ovarian cancer patients than the non-endometritis cohort (Tab. 1).

The mean follow-up period was 9.15 years for the non-endometritis cohort and 9.13 years for the endome- tritis cohort $(p=0.479)$. Associations of endometritis and other risk factors with endometriosis are shown in Table 2. Compared to non-endometritis patients, patients with endometritis had a 1.58-fold adjusted HR of development of endometriosis after adjustment for age and with/without comorbidity (model 1). Compared to patients aged 20-25 years, there were a 1.38-, 1.58-, 1.91-, and 1.59-fold risks of development of endometriosis in patients aged 25-30, $30-35,35-40$, and 40-45 years, respectively. However, patients aged $45-50$ and $50-55$ years had a significantly lower risk, with adjusted HRs of 0.79 and 0.14 , respectively.

Compared to patients without comorbidity, patients with any one of the comorbidities had a 1.59-fold risk of developing endometriosis. After adjustment for age and the comorbidities of uterine leiomyoma, rheumatoid arthritis, infertility, and allergic diseases (model 2), patients with endometritis had a notably higher risk of endometriosis than non-endometritis patients [adjusted HR $(95 \% \mathrm{Cl})$ 1.55 (1.45-1.65)]. The association between age and endometriosis in model 2 was similar to that in model 1. Compared to 
Table 2. Incidence and hazard ratio of endometriosis for endometritis patients compared to controls

\begin{tabular}{|c|c|c|c|c|c|c|c|c|c|}
\hline & \multirow[b]{3}{*}{ Event } & \multirow[b]{3}{*}{ PY } & \multirow[b]{3}{*}{ IR } & \multirow{2}{*}{\multicolumn{2}{|c|}{$\begin{array}{l}\text { Crude } \\
\text { Model 1a }^{\text {a }}\end{array}$}} & \multicolumn{4}{|l|}{ Adjusted } \\
\hline & & & & & & \multirow[b]{2}{*}{ HR $(95 \%$ Cl) } & \multirow{2}{*}{$\begin{array}{l}\text { Model } 2^{b} \\
\text { p-value }\end{array}$} & \multirow[b]{2}{*}{ HR (95\% Cl) } & \multirow[b]{2}{*}{ p-value } \\
\hline & & & & HR (95\% CI) & p-value & & & & \\
\hline \multicolumn{10}{|c|}{ Endometritis } \\
\hline No & 3345 & 615940 & 5.43 & Reference & & Reference & & Reference & \\
\hline Yes & 1348 & 153604 & 8.78 & $1.62(1.52-1.72)$ & $<0.001$ & $1.60(1.50-1.70)$ & $<0.001$ & $1.57(1.47-1.67)$ & $<0.001$ \\
\hline \multicolumn{10}{|l|}{ Age } \\
\hline $20-25$ & 663 & 146805 & 4.52 & Reference & & Reference & & Reference & \\
\hline $25-30$ & 938 & 147361 & 6.37 & $1.41(1.27-1.55)$ & $<0.001$ & $1.42(1.29-1.57)$ & $<0.001$ & $1.41(1.28-1.56)$ & $<0.001$ \\
\hline $30-35$ & 960 & 132994 & 7.22 & $1.60(1.45-1.77)$ & $<0.001$ & $1.65(1.49-1.83)$ & $<0.001$ & $1.60(1.45-1.78)$ & $<0.001$ \\
\hline $35-40$ & 1056 & 120746 & 8.75 & $1.94(1.76-2.14)$ & $<0.001$ & $1.96(1.78-2.16)$ & $<0.001$ & $1.85(1.68-2.04)$ & $<0.001$ \\
\hline $40-45$ & 774 & 106683 & 7.26 & $1.61(1.45-1.79)$ & $<0.001$ & $1.58(1.43-1.75)$ & $<0.001$ & $1.43(1.29-1.59)$ & $<0.001$ \\
\hline $45-50$ & 277 & 76673 & 3.61 & $0.80(0.70-0.92)$ & 0.002 & $0.77(0.67-0.89)$ & $<0.001$ & $0.69(0.60-0.80)$ & $<0.001$ \\
\hline $50-55$ & 25 & 38282 & 0.65 & $0.14(0.10-0.22)$ & $<0.001$ & $0.14(0.09-0.20)$ & $<0.001$ & $0.12(0.08-0.18)$ & $<0.001$ \\
\hline \multicolumn{10}{|c|}{ Childbirth } \\
\hline No & 3458 & 584540 & 5.92 & Reference & & Reference & & Reference & \\
\hline Yes & 1235 & 185003 & 6.68 & $1.12(1.05-1.20)$ & 0.001 & $0.87(0.81-0.93)$ & $<0.001$ & $0.87(0.81-0.93)$ & $<0.001$ \\
\hline \multicolumn{10}{|c|}{ Comorbidity } \\
\hline No & 3444 & 630892 & 5.46 & Reference & & Reference & & & \\
\hline Yesc & 1249 & 138652 & 9.01 & $1.63(1.52-1.73)$ & $<0.001$ & $1.60(1.50-1.71)$ & $<0.001$ & & \\
\hline \multicolumn{10}{|c|}{ Uterine leiomyoma } \\
\hline No & 4267 & 740818 & 5.76 & Reference & & & & Reference & \\
\hline Yes & 426 & 28726 & 14.83 & $2.55(2.31-2.81)$ & $<0.001$ & & & $2.67(2.40-2.96)$ & $<0.001$ \\
\hline \multicolumn{10}{|c|}{ Rheumatoid arthritis } \\
\hline No & 4661 & 765068 & 6.09 & Reference & & & & Reference & \\
\hline Yes & 32 & 4476 & 7.15 & $1.16(0.82-1.64)$ & 0.403 & & & $1.13(0.79-1.59)$ & 0.507 \\
\hline \multicolumn{10}{|c|}{ Ovarian cancer } \\
\hline No & 4692 & 769246 & 6.10 & Reference & & & & Reference & \\
\hline Yes & 1 & 298 & 3.36 & $0.54(0.08-3.84)$ & 0.539 & & & $0.43(0.06-3.09)$ & 0.405 \\
\hline \multicolumn{10}{|c|}{ Infertility } \\
\hline No & 4500 & 752153 & 5.98 & Reference & & & & Reference & \\
\hline Yes & 193 & 17391 & 11.10 & $1.83(1.59-2.11)$ & $<0.001$ & & & $1.44(1.24-1.66)$ & $<0.001$ \\
\hline \multicolumn{10}{|c|}{ Allergic disease } \\
\hline No & 3930 & 670894 & 5.86 & Reference & & & & Reference & \\
\hline Yes & 763 & 98650 & 7.73 & $1.30(1.20-1.40)$ & $<0.001$ & & & $1.24(1.15-1.35)$ & $<0.001$ \\
\hline
\end{tabular}

Event: No. patients with endometriosis; $\mathrm{PY}$ - person-years; IR — incidence rate, per 1,000-person years; $\mathrm{HR}$ - hazard ratio; $\mathrm{Cl}$ - confidence interval

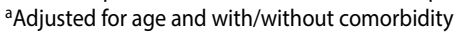

${ }^{b}$ Adjusted for age, uterine leiomyoma, rheumatoid arthritis, ovarian cancer, infertility, and allergic disease

cPatients with any one of the comorbidities were classified as the comorbidity group

patients without rheumatoid arthritis, infertility and allergic diseases, patients with these diseases exhibited positive association with the development of endometriosis.

Analysis of stratification by age and comorbidity are shown in Table 3. Except for patients older than 50 years, there were significantly higher risks of endometriosis in patients with endometritis than in non-endometritis patients in every age stratification (adjusted HR 1.33-2.16). Among patients without any one of the comorbidities, patients with endometritis had a 1.55-fold risk of endometriosis compared to non-endometritis patients. Among patients with any one of the comorbidities, patients with endometritis had a 1.64-fold risk of endometriosis compared to non-endometritis patients. Endometritis was significantly associated with endometriosis among patients with uterine leiomyoma [adjusted HR (95\% Cl) 1.63 (1.34-1.98)], infertility [adjusted 


\begin{tabular}{|l|l|l|l|l|}
\hline \multicolumn{5}{|l}{ Table 3. Incidence and hazard ratio of endometriosis for endometritis } \\
patients compared to controls stratified by age, childbirth, and \\
comorbidities
\end{tabular}

$\mathrm{HR}$ - hazard ratio; $\mathrm{Cl}$ - confidence interval; ${ }^{\mathrm{a} A d j u s t e d ~ f o r ~ o t h e r ~ c o v a r i a t e s ~}$

$\mathrm{HR}(95 \% \mathrm{Cl}) 1.58(1.18-2.11)]$, and allergic diseases [adjusted $\mathrm{HR}(95 \% \mathrm{Cl}) 1.50(1.29-1.75)]$.

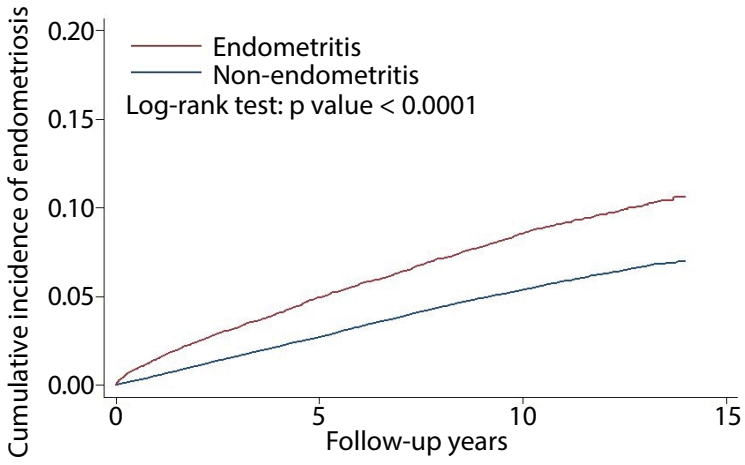

Figure 2. Cumulative incidence curve of endometriosis between endometritis patients and non-endometritis patients

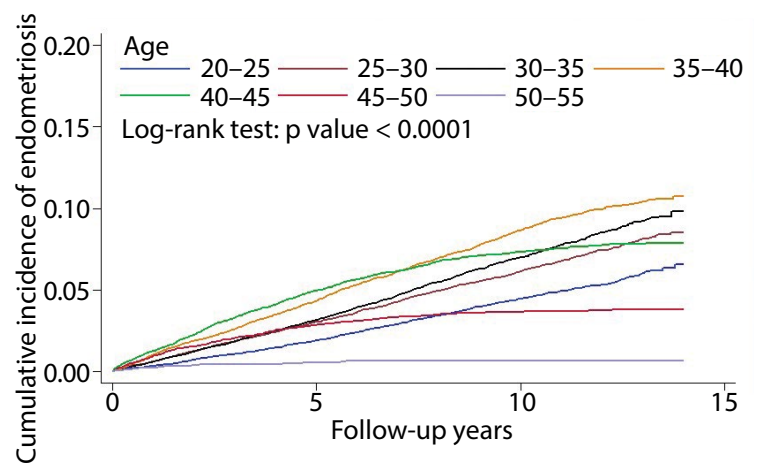

Figure 3. Cumulative incidence curve of endometriosis in each age group

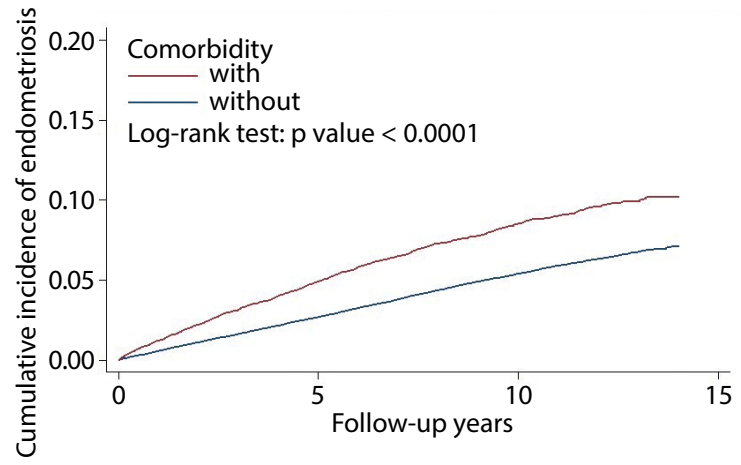

Figure 4. Cumulative incidence curve of endometriosis in patients with comorbidity and without comorbidity

During the whole follow-up period there was a significantly higher cumulative incidence of endometriosis for patients with endometritis than patients without endometritis (log-rank $p<0.0001)$ (Fig. 2). There was a considerably different cumulative incidence of endometriosis in the different age stratifications (log-rank $p<0.0001$ ) (Fig. 3). Patients with comorbidity had significantly higher cumulative incidences of endometriosis than patients without comorbidity (log-rank $p<0.0001$ ) (Fig. 4). Among patients with any one of the comorbidities, patients with endometritis had 


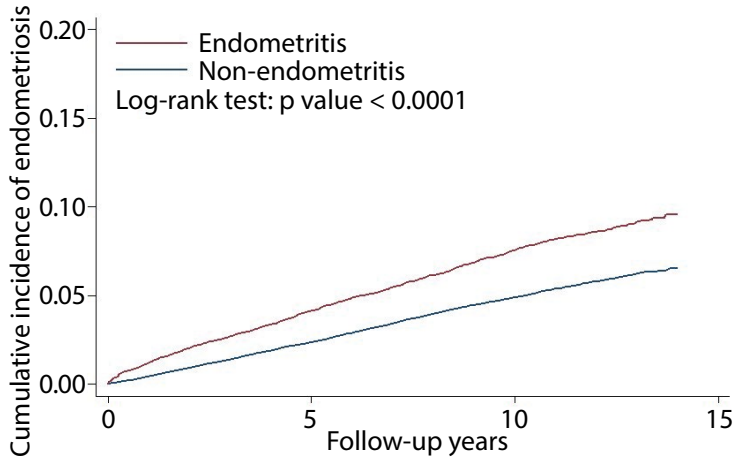

Figure 5. Cumulative incidence curve of endometriosis between patients with endometritis and non-endometritis, among patients without any of the comorbidities listed in Table 2

particularly higher cumulative incidences of endometriosis than non-endometritis patients (log-rank $p<0.0001$ ) (Fig. 5). Among patients without comorbidity, those with endometritis also had considerably higher cumulative incidences of endometriosis than non-endometritis patients (log-rank $\mathrm{p}<0.0001$ ) (Fig. 6).

\section{DISCUSSION}

This nationwide retrospective cohort study revealed that patients with endometritis had a 1.5 -fold increase in the risk of developing endometriosis, compared with women without endometritis. Uterine leiomyoma, infertility, rheumatoid arthritis, and allergic diseases exhibit higher incidences in women with endometritis. It is not known why the frequency of ovarian cancer was lower in patients with endometritis. Although we found a significant association of endometritis with endometriosis, this association should be viewed with caution: the association between endometritis and the incidence of endometriosis may result from a causal connection, which may indicate that endometritis might incline women to the development of endometriosis. In addition, there might be a third confounding variable, which implies that there is an overlapping risk factor or pathological process which alters the development of endometritis and endometriosis.

Local chronic inflammation has been suggested as a risk factor for the development of endometriosis [9-11]. Increasing levels of monocyte chemotactic protein 1 (MCP-1), interleukin (IL)-8, IL-6, IL-1 $\beta$, and tumor necrosis factor (TNF)- $\alpha$ enhance the implantation of ectopic endometrial tissue [12-14]. In addition, the inflammatory cytokines and chemokines secreted by ectopic endometriotic tissues attract macrophages to the peritoneal cavity, which enhances inflammation [15]. The number of activated macrophages in the peritoneal cavity of patients with endometriosis is elevated [16]. It is possible that inflammation in the peritoneal cavity may be related to infections [17], with in-

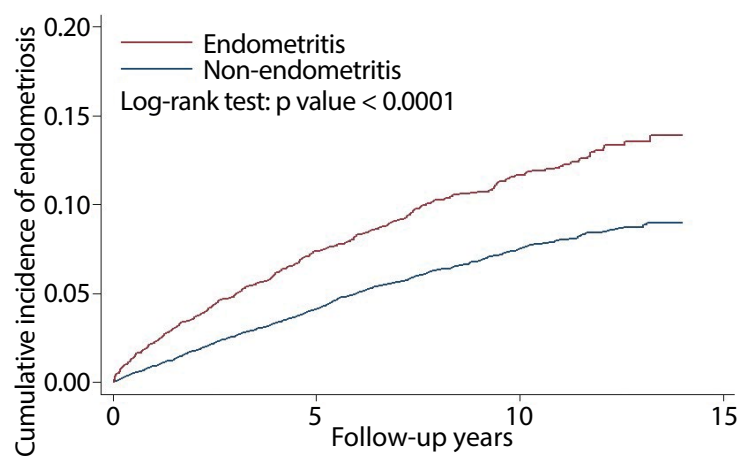

Figure 6. Cumulative incidence curve of endometriosis between patients with endometritis and non-endometritis, among patients with any one of the comorbidities listed in Table 2

creased production of inflammatory cytokines through bacterial infection further enhancing the development of endometriosis [18]. The induction of inflammation may be related to infections in the upper reproductive tract, lower reproductive tract, or pelvis $[17,19,20]$. Bacterial colonization increases the levels of inflammatory mediators, which promote development of endometriosis [18].

Imbalance and inflammatory reactions are two potential factors linked with endometritis and endometriosis. In Rhesus monkeys with endometriosis, the levels of intestinal microflora were changed, with these monkeys showing lower amounts of lactobacilli but higher concentrations of gram-negative bacteria [21]. It was found that the number of $E$. coli in the menstrual blood of patients with endometriosis was elevated. The endotoxin levels in menstrual and peritoneal fluid were also elevated [22]. Bacterial endotoxins could promote inflammation by inducing the expression of inflammatory cytokines and chemokines [23]. The inflammatory cytokines and chemokines could attract macrophages, which can be activated by endotoxins through toll-like receptor 4 (TLR4). Activated macrophages would further sustain/amplify inflammatory reactions [23]. The bacteria present in the uterine cavity and peritoneal fluid might induce the TLR4-mediated growth of endometrial lesions [24]. In cystic fluid of patients with ovarian endometriosis, presence of the Streptococcaceae and Staphylococcaceae families is significantly elevated [25]. The imbalance of endometrial microbiota in the uterine cavity could influence the balance of immune responses which increase inflammation, thus promoting the pathogenesis of endometriosis [26].

The varied concentrations of estradiol and progesterone during the menstrual cycle have significant consequences for the balance of the microbiota, which may promote infections. Estradiol encourages the infiltration of macrophages into the endometrium to reduce the risk of bacterial infections $[27,28]$. A high concentration of progesterone reduces uterus lymphocyte infiltration, which may increase the risk 
of bacterial infections [27, 28]. The growth of eutopic and ectopic endometriotic tissues could be enhanced by treatment with bacterial endotoxins. In endometrial stromal cells and macrophages treated with bacterial endotoxins, levels of hepatocyte growth factor, vascular endothelial cell growth factor (VEGF), IL-6, IL-8, and TNF-a were elevated $[29,30]$. The expression of VEGF is important to sustain the growth of eutopic and ectopic endometriotic tissues [31, 32]. Treating endometrial stromal cells with combined estradiol and lipopolysaccharide significantly increased the proliferation rate [33]. Moreover, the expression levels of IL-6 and TNF-a were higher in macrophages isolated from patients with endometriosis [34]. These findings suggest that estradiol and progesterone levels influence the risk of bacterial infection in the female reproductive tract and promote the expansion of ectopic and eutopic endometriotic tissues to encourage endometriosis.

There are various limitations of this study. First, this is a retrospective cohort study, which makes it hard to define the causation of the two associated diseases. Secondly, we used insurance claims data to select our study population by ICD coding, which could have resulted in misclassification bias. Thirdly, we could not ascertain reasons why participants were lost to follow-up. It should also be noted that patients with endometritis would probably have a higher chance of being diagnosed with endometriosis since they may receive more medical attention to the female reproductive tract than those without the disease. In addition to age and the comorbidities that were adjusted for, there are still some confounding variables. Body mass index (BMI), number of births, use of birth control pills or devices, and length and interval of menstrual cycle were not analyzed in this study. A more detailed prospective cohort study should be conducted to understand the correlation between endometritis and endometriosis better.

In conclusion, the results of this study indicate that patients with endometritis are at higher risk of developing endometriosis compared with patients without endometritis. This indicates that either endometritis predisposes to endometriosis or that some specific pathogenic factors influence the development of both conditions. Although the exact pathological factors are not yet known, these findings make a meaningful contribution to the diagnosis and management of patients with endometritis.

\section{Funding}

This work was supported in part by the Ministry of Science and Technology, Taiwan, Republic of China (MOST105-2628B-039-008-MY3 and MOST107-2320-B-039-049-MY3), the Ministry of Health and Welfare, Taiwan (MOHW108-TDU-B-212-133004), China Medical University Hospital (DMR106-178), China Medical University (CMU107-ASIA-23), Aca- demia Sinica Stroke Biosignature Project (BM10701010021), MOST Clinical Trial Consortium for Stroke (MOST 107-2321B-039-004-), Tseng-Lien Lin Foundation, Taichung, Taiwan, and Katsuzo and Kiyo Aoshima Memorial Funds, Japan.

\section{REFERENCES}

1. Laux-Biehlmann A, d'Hooghe T, Zollner TM. Menstruation pulls the trigger for inflammation and pain in endometriosis. Trends Pharmacol Sci. 2015; 36(5): 270-276, doi: 10.1016/j.tips.2015.03.004, indexed in Pubmed: 25899467.

2. De Graaff AA, D'Hooghe TM, Dunselman GAJ, et al. WERF EndoCost Consortium. The significant effect of endometriosis on physical, mental and social wellbeing: results from an international cross-sectional survey. Hum Reprod. 2013; 28(10): 2677-2685, doi: 10.1093/humrep/det284, indexed in Pubmed: 23847114.

3. McCunn R, Aus der Fünten K, Whalan M, et al. Metastatic or Embolic Endometriosis, due to the Menstrual Dissemination of Endometrial Tissue into the Venous Circulation. Am J Pathol. 1927; 3(2): 93-110.43, indexed in Pubmed: 19969738.

4. D'Hooghe TM, Debrock S. Endometriosis, retrograde menstruation and peritoneal inflammation in women and in baboons. Hum Reprod Update. 2002; 8(1): 84-88, doi: 10.1093/humupd/8.1.84, indexed in Pubmed: 11866244.

5. Khoufache K, Michaud N, Harir N, et al. Anomalies in the inflammatory response in endometriosis and possible consequences: a review. Minerva Endocrinol. 2012; 37(1): 75-92, indexed in Pubmed: 22382616.

6. Kajihara $H$, Yamada $Y$, Kanayama $S$, et al. New insights into the pathophysiology of endometriosis: from chronic inflammation to danger signal. Gynecol Endocrinol. 2011; 27(2): 73-79, doi: 10.3109/09513590.2010.507292, indexed in Pubmed: 20712428.

7. Bertschi D, McKinnon BD, Evers J, et al. Enhanced inflammatory activity of endometriotic lesions from the rectovaginal septum. Mediators Inflamm. 2013; 2013: 450950, doi: 10.1155/2013/450950, indexed in Pubmed: 24453419

8. Wu Y, Kajdacsy-Balla A, Strawn E, et al. Transcriptional characterizations of differences between eutopic and ectopic endometrium. Endocrinology. 2006; 147(1): 232-246, doi: 10.1210/en.2005-0426, indexed in Pubmed: 16195411

9. Kao LC, Germeyer A, Tulac S, et al. Expression profiling of endometrium from women with endometriosis reveals candidate genes for disease-based implantation failure and infertility. Endocrinology. 2003; 144(7): 2870-2881, doi: 10.1210/en.2003-0043, indexed in Pubmed: 12810542.

10. Tao Yu, Zhang Q, Huang W, et al. The peritoneal leptin, MCP-1 and TNF-a in the pathogenesis of endometriosis-associated infertility. Am J Reprod Immunol. 2011;65(4): 403-406, doi: 10.1111/j.1600-0897.2010.00920.x, indexed in Pubmed: 20825374.

11. Lebovic DI, Mueller MD, Taylor RN. Immunobiology of endometriosis. Fertil Steril. 2001; 75(1): 1-10, doi: 10.1016/s0015-0282(00)01630-7, indexed in Pubmed: 11163805.

12. Bedaiwy MA, Falcone T. Peritoneal fluid environment in endometriosis. Clinicopathological implications. Minerva Ginecol. 2003; 55(4): 333-345, indexed in Pubmed: 14581858.

13. Missmer SA, Cramer DW, Cramer DW, et al. The epidemiology of endometriosis. Ann N Y Acad Sci. 2002; 955(1): 11-22; discussion 34, doi: 10.1111/j.1749-6632.2002.tb02761.x, indexed in Pubmed: 11949940.

14. Moreno I, Franasiak JM. Endometrial microbiota-new player in town. Fertil Steril. 2017; 108(1): 32-39, doi: 10.1016/j.fertnstert.2017.05.034, indexed in Pubmed: 28602480.

15. Lin WC, Chang CYY, Hsu YA, et al. Increased Risk of Endometriosis in Patients With Lower Genital Tract Infection: A Nationwide Cohort Study. Medicine (Baltimore). 2016; 95(10): e2773, doi: 10.1097/MD.0000000000002773, indexed in Pubmed: 26962775.

16. Tai FW, Chang CYY, Chiang JH, et al. Association of Pelvic Inflammatory Disease with Risk of Endometriosis: A Nationwide Cohort Study Involving 141,460 Individuals. J Clin Med. 2018; 7(11), doi: 10.3390/jcm7110379, indexed in Pubmed: 30352985.

17. Cicinelli E, De Ziegler D, Nicoletti R, et al. Poor reliability of vaginal and endocervical cultures for evaluating microbiology of endometrial cavity in women with chronic endometritis. Gynecol Obstet Invest. 2009; 68(2): 108-115, doi: 10.1159/000223819, indexed in Pubmed: 19521097. 
18. Kitaya $\mathrm{K}$, Matsubayashi $\mathrm{H}$, Takaya $\mathrm{Y}$, et al. Live birth rate following oral antibiotic treatment for chronic endometritis in infertile women with repeated implantation failure. Am J Reprod Immunol. 2017; 78(5), doi: 10.1111/aji.12719, indexed in Pubmed: 28608596.

19. Moreno I, Codoñer FM, Vilella F, et al. Evidence that the endometrial microbiota has an effect on implantation success or failure. Am J Obstet Gynecol. 2016; 215(6): 684-703, doi: 10.1016/j.ajog.2016.09.075, indexed in Pubmed: 27717732.

20. Miles SM, Hardy BL, Merrell DS. Investigation of the microbiota of the reproductive tract in women undergoing a total hysterectomy and bilateral salpingo-oopherectomy. Fertil Steril. 2017; 107(3): 813-820. e1, doi: 10.1016/j.fertnstert.2016.11.028, indexed in Pubmed: 28069180.

21. Bailey MT, Coe CL. Endometriosis is associated with an altered profile of intestinal microflora in female rhesus monkeys. Hum Reprod. 2002; 17(7): 1704-1708, doi: 10.1093/humrep/17.7.1704, indexed in Pubmed: 12093827.

22. Khan KN, Kitajima M, Hiraki K, et al. Escherichia coli contamination of menstrual blood and effect of bacterial endotoxin on endometriosis. Fertil Steril. 2010; 94(7): 2860-3.e1, doi: 10.1016/j.fertnstert.2010.04.053, indexed in Pubmed: 20627244.

23. Khan KN, Kitajima M, Hiraki K, et al. Toll-like receptors in innate immunity: role of bacterial endotoxin and toll-like receptor 4 in endometrium and endometriosis. Gynecol Obstet Invest. 2009; 68(1): 40-52, doi: 10.1159/000212061, indexed in Pubmed: 19365133.

24. Khan KN, Fujishita A, Hiraki K, et al. Bacterial contamination hypothesis: a new concept in endometriosis. Reprod Med Biol. 2018; 17(2): 125-133, doi: 10.1002/rmb2.12083, indexed in Pubmed: 29692669.

25. Khan KN, Fujishita A, Masumoto $\mathrm{H}$, et al. Molecular detection of intrauterine microbial colonization in women with endometriosis. Eur J Obstet Gynecol Reprod Biol. 2016; 199: 69-75, doi: 10.1016/j. ejogrb.2016.01.040, indexed in Pubmed: 26901400.

26. Mitchell CM, Haick A, Nkwopara E, et al. Colonization of the upper genital tract by vaginal bacterial species in nonpregnant women. Am J Obstet
Gynecol. 2015; 212(5): 611.e1-611.e9, doi: 10.1016/j.ajog.2014.11.043, indexed in Pubmed: 25524398.

27. Herath S, Fischer DP, Werling D, et al. Expression and function of Toll-like receptor 4 in the endometrial cells of the uterus. Endocrinology. 2006; 147(1): 562-570, doi: 10.1210/en.2005-1113, indexed in Pubmed: 16223858.

28. Beagley KW, Gockel CM. Regulation of innate and adaptive immunity by the female sex hormones oestradiol and progesterone. FEMS Immunol Med Microbiol. 2003; 38(1): 13-22, doi: 10.1016/S0928-8244(03)00202-5, indexed in Pubmed: 12900050.

29. Khan KN, Kitajima M, Inoue T, et al. Additive effects of inflammation and stress reaction on Toll-like receptor 4-mediated growth of endometriotic stromal cells. Hum Reprod. 2013; 28(10): 2794-2803, doi: 10.1093/humrep/det280, indexed in Pubmed: 23842561.

30. Imamura T, Khan KN, Fujishita A, et al. Toll-like receptor 4-mediated growth of endometriosis by human heat-shock protein 70 . Hum Reprod. 2008; 23(10): 2210-2219, doi: 10.1093/humrep/den195, indexed in Pubmed: 18596029.

31. Bourlev V, Volkov N, Pavlovitch S, et al. The relationship between microvessel density, proliferative activity and expression of vascular endothelial growth factor- $A$ and its receptors in eutopic endometrium and endometriotic lesions. Reproduction. 2006; 132(3): 501-509, doi: 10.1530/rep.1.01110, indexed in Pubmed: 16940291.

32. Takehara $\mathrm{M}$, Ueda $\mathrm{M}$, Yamashita $\mathrm{Y}$, et al. Vascular endothelial growth factor A and C gene expression in endometriosis. Hum Pathol. 2004; 35(11): 13691375, doi: 10.1016/j.humpath.2004.07.020, indexed in Pubmed: 15668894.

33. Khan KN, Kitajima M, Inoue T, et al. $17 \beta$-estradiol and lipopolysaccharide additively promote pelvic inflammation and growth of endometriosis. Reprod Sci. 2015; 22(5): 585-594, doi: 10.1177/1933719114556487, indexed in Pubmed: 25355803.

34. Montagna P, Capellino S, Villaggio B, et al. Peritoneal fluid macrophages in endometriosis: correlation between the expression of estrogen receptors and inflammation. Fertil Steril. 2008; 90(1): 156-164, doi: 10.1016/j. fertnstert.2006.11.200, indexed in Pubmed: 17548071. 